\title{
Development and Evaluation of Indomethacin Controlled Release Press Coated Tablets
}

\author{
Muhammad Rashedul Islam ${ }^{1}$, Md. Elias-Al-Mamun ${ }^{1}$, Md. Mizanur Rahman Moghal ${ }^{2}$ \\ and Md. Habibur Rahman ${ }^{1}$ \\ ${ }^{1}$ Department of Pharmaceutical Technology, Faculty of Pharmacy, University of Dhaka, Dhaka-1000, \\ Bangladesh \\ ${ }^{2}$ Department of Pharmacy, Mawlana Bhasani Science and Technology University, Tangail-1902, Bangladesh
}

Received: November 17, 2015; Accepted: December 15, 2015; Published (web): January 31, 2016

\begin{abstract}
In the present work, several batches of indomethacin press coated tablets were prepared with drug and Avicel PH 102 utilizing the press coating technology. The core tablet was compression coated with minimal compression pressure. The compression coating mixture was formulated using various amount of lactose and xanthan gum which was used as the release retarding agent. Three formulations (IX-1, IX-2 and IX-3) were designed to evaluate the release profile as function of xanthan gum load. In vitro drug release testing demonstrated that the drug release was inversely proportional to the amount of xanthan gum in the coating formulations. In addition, formulation IX-2 was modified by incorporating hydroxypropyl methyl cellulose (HPMC) 15 cps into the compression coating formulation to understand their effects on drug release. The formulation was evaluated for its properties and correlated with in vitro and kinetic release studies. Incorporation of HPMC caused the highest fraction of drug to be released in the dissolution fluid. The physico-chemical properties of the excipients can be held responsible for the discrepancy in release rate of indomethacin. From kinetic analysis drug release was found to follow Higuchi mechanism for all the formulations. Overall, the study concluded that excipients present in the coating formulations make a significant impact on drug release.
\end{abstract}

Key words: Indomethacin, hydroxypropyl methyl cellulose, press coating technology

\section{INTRODUCTION}

Compared to polymer coating, the press-coating technique has the advantage of being used without solvents and requiring a relatively short manufacturing process. Composition of the barrier layer controls the mechanism of effecting the lag time. Polymer blends could be a solution for creating a new composition, exhibiting the appropriate flexibility for the adjustment of drug release delay. ${ }^{1,2}$ In general, a press coated tablet consists of an inner core tablet and an outer coating shell. The outer layer surrounds the inner core. Selection of outer layer materials has a significant impact on the performance of the tablet, including the coating's mechanical

Correspondence to: Muhammad Rashedul Islam Tel: 88-01558299802; Fax: 88-02-8615583

E-mail: rashed1505@yahoo.com

Dhaka Univ. J. Pharm. Sci. 14(2): 187-192, 2015 (December) strength, drug release characteristics, and tablet stability. Press coating may be classified as a chronopharmaceutical technology, in that it provides a solid dosage form for drug delivery in a pulsatile fashion rather than continuously with predetermined time, at the site following oral administration. ${ }^{3,4}$

Indomethacin is a non-steroidal antiinflammatory indole derivative. Indomethacin is chemically 1-(4-chlorobenzoyl)-5-methoxy-2methyl- $1 H$-indole -3 -acetic acid. Indomethacin has been shown to be an effective anti-inflammatory agent, appropriate for long-term use in rheumatoid arthritis, alkylosing spondylitis and osteoarthritis. It is practically insoluble in water and sparingly soluble in alcohol. ${ }^{5}$ This drug delivery system is designed to deliver the drug at such a time when it could be most needful to patient of rheumatoid arthritis. 
The press coated tablets containing indomethacin in the inner core was formulated with an outer shell by different weight ratio of hydrophobic polymer (xanthan gum) and hydrophilic polymer (HPMC).

Xanthan gum is a high-molecular-mass anionic polysaccharide produced by pure culture aerobic fermentation of carbohydrate with bacterium Xanthomonas campestris. ${ }^{6}$ It has been used as a matrix ingredient for a biodegradable, implantable, controlled release dosage form. ${ }^{7}$ Xanthan gum has the potential advantage of drug release with zero order release kinetics. Nonionic cellulose ethers, and most frequently hydroxypropyl methyl cellulose (HPMC) have been widely studied for their applications in oral sustained release systems. ${ }^{8}$ When in contact with water, HPMC hydrates rapidly and forms a gelatinous barrier layer around the tablet. The rate of drug release from HPMC matrix is dependent on various factors such as type of polymer, drug, polymer/drug ratio, particle size of drug and polymer, and the type and amount of fillers used in the formulation. ${ }^{9}$

The main purpose of the present study was to prepare xanthan gum and HPMC based press coated tablets of indomethacin and evaluate its release mechanism. Their release patterns were compared using Higuchi's model.

\section{MATERIALS AND METHODS}

\section{Materials}

Indomethacin (active drug) was purchased from Nipa Pharmaceuticals Limited. Xanthan gum is collected from sole agent Orchid Chemicals (India).
Microcrystalline Cellulose (Avicel PH 102), Hydroxy propyl methyl cellulose, Lactose and Magnesium stearate were kind gift from Nipa Pharmaceuticals Limited. Potassium dihydrogen phosphate of Merck (Germany), $\mathrm{HCl}$ (37\% w/v) of Merck (Germany) and purified water of Research Laboratory (Bangladesh) were used as the reagents. Among the instruments, vernier caliper of Erweka (Germany), Shimadzu UV Spectrophotometer (Japan), hardness tester and dissolution tester were from Erweka (Germany), Pharmatest disintegration tester (Germany), mini drum blender of Cadmach Machinery (India), friability tester of Logan (USA), Hanna $\mathrm{pH}$ meter (Portugal), stainless steel sieve (Bangladesh) and Manesty 16 station compression machine (England) were used.

\section{Methods}

Preparation of matrix tablet. For tableting the cores, indomethacin and Avicel PH 102 were mixed in a laboratory tumblar for 30 minutes. Magnesium stearate was added and mixed for an additional 5 minutes. Cores were compressed with minimum compression force using round, flat punches $(7.5 \mathrm{~mm}$ diameter). Components of the coat were mixed in a laboratory tumbler for 30 minutes. Core centralization and machine operation were undertaken using by a standardized manual process. Half of the powder mass for one tablet coat was weighed into a die (11.5 $\mathrm{mm}$ in diameter). A lower coating layer was consolidated and the core centered on an even bed. The remaining powder was then added to the die..$^{10,11}$

Table 1. Composition of indomethacin press coated tablets.

\begin{tabular}{lcccc}
\hline Ingredient & IX-1 & IX-2 & IX-3 & IX-HPMC \\
\hline Core & & & & \\
Indomethacin & $75 \mathrm{mg}$ & $75 \mathrm{mg}$ & $75 \mathrm{mg}$ & $75 \mathrm{mg}$ \\
Avicel PH 102 & $75 \mathrm{mg}$ & $75 \mathrm{mg}$ & $75 \mathrm{mg}$ & $75 \mathrm{mg}$ \\
Magnesium stearate & $1.5 \mathrm{mg}$ & $1.5 \mathrm{mg}$ & $1.5 \mathrm{mg}$ & $1.5 \mathrm{mg}$ \\
Coat & & & \\
Lactose & $510 \mathrm{mg}$ & $483 \mathrm{mg}$ & $453 \mathrm{mg}$ & $483 \mathrm{mg}$ \\
Xanthan gum & $57 \mathrm{mg}$ & $85.5 \mathrm{mg}$ & $114 \mathrm{mg}$ & $79.8 \mathrm{mg}$ \\
Magnesium stearate & $1.5 \mathrm{mg}$ & $1.5 \mathrm{mg}$ & $1.5 \mathrm{mg}$ & $1.5 \mathrm{mg}$ \\
HPMC & & & $5.7 \mathrm{mg}$ \\
\hline
\end{tabular}


Formulation IX-1, IX-2 and IX-3 were designed where the ratio of lactose to xanthan gum was kept at 90:10, 85:15 and 80:20 ratios, as shown in table 1 . Next, a fixed amount of $5.7 \mathrm{mg} / \mathrm{tab}$ of HPMC was added to the compression coating material replacing the equivalent amount of xanthan gum. Now drug release profile was evaluated as a function of xanthan load and HPMC load present in the compression coat.

\section{Preparation of dissolution media}

Phosphate buffer (pH 7.2). $13.60 \mathrm{gm}$ of potassium dihydrogen phosphate was taken in to a $1000 \mathrm{ml}$ volumetric flask, dissolved in and diluted up to the mark with distilled water. The concentration of the solution was $0.1 \mathrm{M}$. Then $500 \mathrm{ml}$ of this solution was taken in to an another $1000 \mathrm{ml}$ volumetric flask, $36 \mathrm{ml} 0.1 \mathrm{M}$ sodium hydroxide was added and finally the volume was made up to $1000 \mathrm{ml}$ with distilled water.

Dissolution study. The dissolution of the prepared matrix tablets was studied by using Erweka dissolution tester (USP Paddle method), with a rotation of $50 \mathrm{rpm}$ at $37 \pm 0.5{ }^{\circ} \mathrm{C}$ placing 1-liter dissolution media in each vessel. Three tablets from each batch were taken into three vessels. It means the experiment was carried out in triplicate and each time we ran two batches. After each specified time intervals $5 \mathrm{ml}$ of the dissolution media was withdrawn from each vessel for assay of drug content and was replaced by a fresh portion of medium of the same volume. The collected sample was then filtered through Whattman no. 41 filter paper. Then $1 \mathrm{ml}$ filtrate was taken into a 50-ml volumetric flask and diluted up to the mark with dissolution media. The absorbance of the samples was measured at $320 \mathrm{~nm}$ by using Shimadzu UV spectrophotometer. ${ }^{12}$ Now the percent release of drug was calculated from the measured absorbance. The dissolution was performed using phosphate buffer, $\mathrm{pH}$ 7.2.

Release kinetics. All data obtained from in vitro release studies were fitted to kinetic equation to find out the mechanism of drug release from the indomethacin press coated tablets. In this study, the higuchi kinetic model was used (equation 1): ${ }^{13}$

$$
\mathbf{M}_{\mathbf{t}}=\mathbf{M}_{\mathbf{0}}+\mathbf{K}_{\mathbf{H}} \mathbf{t}^{0.5}
$$

Where $\mathbf{M}_{t}$ is the amount of drug dissolved in time $\mathrm{t}, \mathrm{M}_{0}$ is the initial amount of drug and $\mathrm{K}_{\mathrm{H}}$ is the Higuchi rate constant.

Statistical analysis. In this study, one-way analysis of variance (ANOVA) (performed at 5\% significance level using SPSS Version 16.0) was used to compare the difference of dissolution profiles of the test matrix tablets.

\section{RESULTS AND DISCUSSION}

In the present experiment, the flow properties of the excipients have been evaluated. Carr's compressibility index and Hausner ratio have been calculated and presented in table 2. It was found that all the individual excipients and the mixture had the flow parameters within the range allowing desirable flow property.

Table 2. Flow property of different mixtures of press coated tablets.

\begin{tabular}{lcc}
\hline Ingredients / Mixtures & $\begin{array}{c}\text { Carr's } \\
\text { compressibilty }\end{array}$ & Hausner ratio \\
\hline Indomethacin & 30.58 & 1.15 \\
Xanthan gum & 25.64 & 1.34 \\
Lactose & 12.36 & 1.35 \\
Lactose: Xanthan gum (85:15) & 13.56 & 1.22 \\
Lactose: Xanthan gum (80:20) & 14.13 & 1.34 \\
Lactose: Xanthan gum (90:10) & 13.65 & 1.23 \\
HPMC: Xanthan gum & 14.20 & 1.28 \\
\hline
\end{tabular}

Release profiles of indomethacin from xanthan gum based press coated tablet preparation. Figure 1 shows the results of the indomethacin release from a press coated tablet. The compression coat carried different amount of xanthan gum increased gradually from formulation IX-1 to IX-3. Formulation IX-3, IX-2 and IX-1 contained 114 $\mathrm{mg}, 85.5 \mathrm{mg}$ and $57 \mathrm{mg}$ of xanthan gum per tablet which presented the lactose to xanthan ratio of 80:20, 85:15 and 90:10 respectively. The tablet parameters i.e., thickness, friability, diameter and weight variation data was given in table 3 . From ANOVA 
analysis, a significant group effect was observed for all the formulations $(\mathrm{P}<0.01)$. It was found that, increasing the xanthan gum load reduced the rate and extent of drug release. Formulation IX-1 released approximately $96 \%$ indomethacin after 12 hours of dissolution period. Approximately $46 \%$ and $32 \%$ of

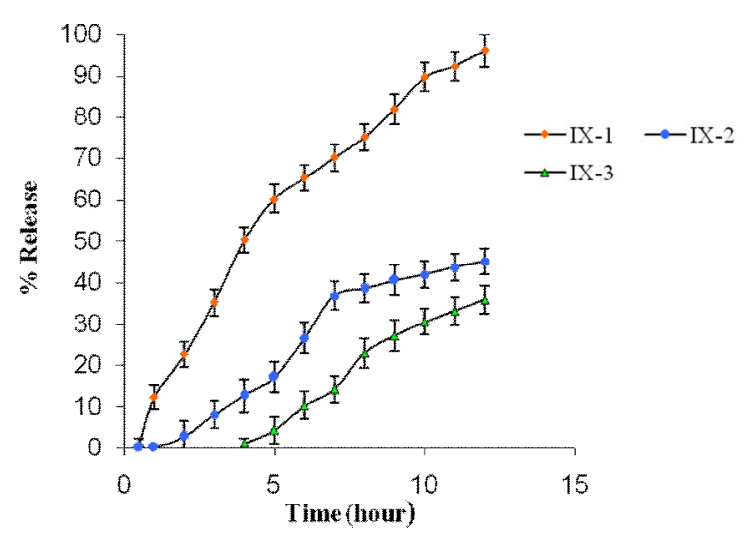

Figure 1. Release profile of indomethacin from xanthan gum based press coated tablets.

indomethacin was released after 12 hours from IX-2 and IX-3 respectively. A lag phase was observed for all the three formulations which were due to the formation of gel by swelling of xanthan gum at the initiation of dissolution process. Xanthan gum is a hydrophilic matrix and forms swellable matrix when it comes in contact with water. Increased xanthan gum load increased the strength of the gel which strongly retarded drug release. ${ }^{14}$ Again, increased proportion of xanthan gum increased the tortuosity of the matrix which ultimately increased the diffusion path-length of drug from the core tablet. As a result, drug release was reduced significantly with the increment of xanthan gum load in the compression coat. ${ }^{15}$ The release profiles of different formulations were evaluated kinetically. As shown in figure 2, higuchi model fits with high correlation coefficients $\left(\mathrm{r}^{2}>0.98\right)$ for all the formulations indicating the drug release followed matrix diffusion process. The Higuchi release rate was found highest $\left(35.38 \% / \mathrm{hr}^{-}\right.$ 1/2) with formulation IX-1 which contained least amount of xanthan gum in the compression coat. Formulation IX-3, containing the highest amount of xanthan gum in the coat exhibited least value for
Higuchi release rate $\left(19.53 \% / \mathrm{hr}^{-1 / 2}\right)$. The results indicate that, it is possible to modulate the Higuchi release rate of press-coated tablets by varying the amount of xanthan gum in the coating formulation. A linear relationship between xanthan gum load in the coat and Higuchi release rate was found.

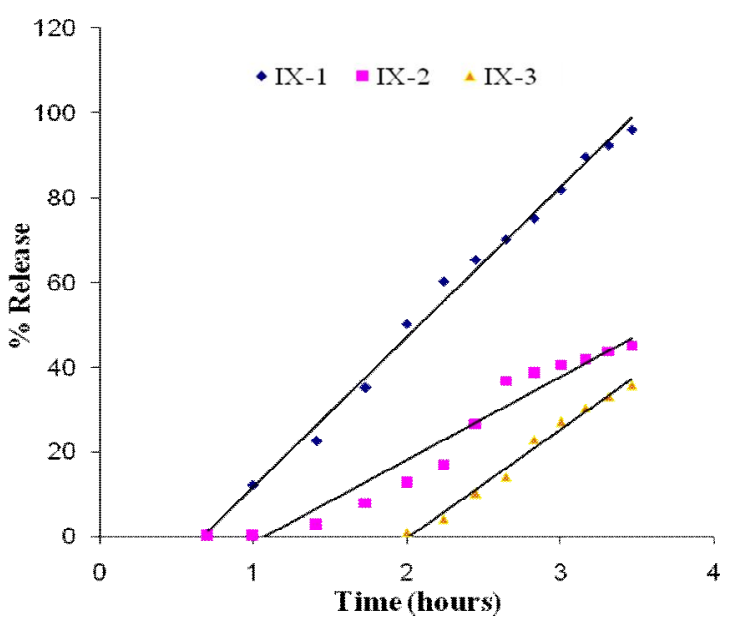

Figure 2. Effect of xanthan gum load on Higuchi release of indomethacin.

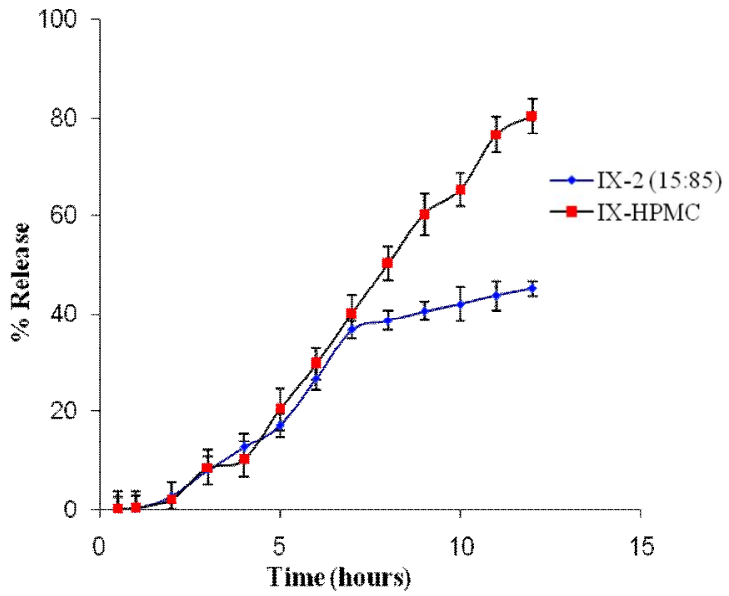

Figure 3. Release profile of indomethacin from HPMC based press coated tablets.

Release profiles of indomethacin from HPMC based press coated tablet preparation. In the present study, HPMC $15 \mathrm{cps}$ was incorporated into the compression coat to assess its effect on drug release. Significant difference was found in release profile when HPMC $15 \mathrm{cps}$ was added into the system. The flow properties of IX-HPMC press coated tablets were shown in table 2 and physical 
properties of IX-HPMC press coated tablets were shown in table 3 . HPMC $15 \mathrm{cps}$ is a class of hydrophilic gel forming agents. It is preferred by the formulators to modulate drug release mainly due to its claim to form strong viscous gel in contact with water. ${ }^{16}$ Formulation IX-HPMC was designed to evaluate the effect of HPMC on drug release from central core matrix tablet. Figure 3 shows the release profile of indomethacin from HPMC loaded press coated tablets. An amount corresponding to $5.7 \mathrm{mg}$ of
HPMC was included in the compression coating formulation by replacing equivalent amount of xanthan gum. Again, HPMC loaded dosage forms have previously been claimed to release drug in near zero order kinetics. ${ }^{17}$ Formulation IX-HPMC was compared with formulation IX-2 in terms of release profile. Again ANOVA analysis showed a significant group effect $(p<0.01)$ in release pattern. It is found that release pattern of indomethacin from IX-HPMC

Table 3. Physical properties of xanthan gum based press coated tablets $(n=10)$.

\begin{tabular}{lcccc}
\hline Parameters & IX-1 & IX-2 & IX-3 & IX2-HPMC \\
\hline Thickness (mm) & 5.5 & 5.5 & 5.5 & 5.5 \\
Diameter (mm) & 11.5 & 11.5 & 11.5 & 11.5 \\
Friability (\%) & 0.32 & 0.20 & 0.29 & 0.24 \\
Weight (mg) & 719.23 & 719.70 & 719.46 & 721.50 \\
Hardness (N) & 67 & 72 & 74 & 78 \\
\hline
\end{tabular}

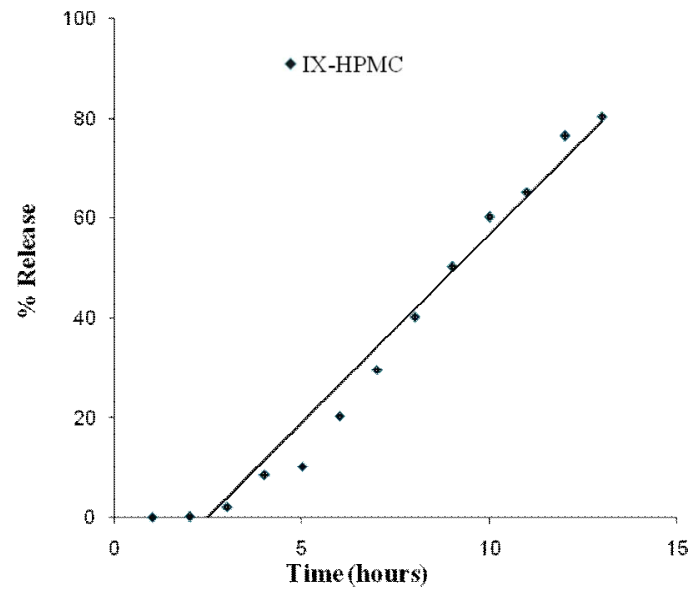

Figure 4. Effect of HPMC on Higuchi release of indomethacin.

was almost superimposable on that of IX-2 for up to 7 hours. After which, extensive release of indomethacin has occurred. After 12 hours of dissolution period, more than $80 \%$ of the active ingredient has been released from IX-HPMC whereas only $46 \%$ was released from IX-2. After the lag phase of first hour, release of drug was more linear from HPMC loaded press coated tablets than that of IX-2. Figure 4 shows the higuchi release profile of indomethacin from HPMC loaded press coated tablets. The first phase of reduced release can be attributed to the formation of gel by HPMC present in the coat whereas the second phase of rapid release was due to the attrition of gel by the solvent and consequent solubulization of HPMC itself. ${ }^{18,19}$

\section{CONCLUSION}

Release of drugs from the compression coated tablet follows three consecutive steps: 1) penetration of dissolution media into the compressed coated tablet, 2) swelling or erosion of hydrophilic polymer and 3) breakdown of outer coating into two halves due to swelling or erosion of hydrophilic polymer used in coating. The experiment indicates that, it is possible to design controlled release press coated tablets that is able to deliver drug at the desired rate. The rate and extent of drug release can be modulated accordingly by varying the type and amount of ratemodifiers.

\section{ACKNOWLEDGEMENT}

The authors are thankful to Eskayef BD. Ltd., Bangladesh for providing laboratory facilities.

\section{REFERENCES}

1. Andrews, G.P., Jones, D.S., Diak, O.A., McCoy, C.P., Watts, O.K. and McGinity, J.W. 2008. The manufacture and 
characterisation of hot-melt extruded enteric tablets. Eur. $J$. Pharm. Biopharm. 69, 264-273.

2. Yoshihiro, T., Hiroyuki, O. and Makoto, O. 2009. Non-invasive and rapid analysis for observation of internal structure of press-coated tablet using X-ray computed tomography. Drug. Dev. Ind. Pharm. 35, 678-682.

3. Lin, S.Y. and Kawashima, Y. 2012. Current status and approaches to developing press-coated chronodelivery drug systems. J. Contr. Rel. 157, 331-353.

4. Swati, C.J. and Chandrakala, R.P. 2014. Application of design of experiment for Polyox and Xanthan Gum coated floating pulsatile delivery of Sumatriptan Succinate in Migraine treatment. Biomed. Res. Int. 2014, 547212.

5. Purpora, R., Massad, W., Ferrari, G., Reynoso, E., Criado, S., Miskosi, S., Pajares, A. and Garcia, N.A. 2013. The NSAIDs indomethacin and diflunisal as scavengers of photogenerated reactive oxygen species. Photochem. Photobiol. 89, 1463-1470.

6. Ali, A., Iqbal, M., Akhtar, N., Khan, H.M., Ullah, A., Uddin, M and Khan, M.T. 2013. Assessment of xanthan gum based sustained release matrix tablets containing highly water soluble propranolol HCl. Acta. Pol. Pharm. 70, 283-289.

7. Kar, R., Mohapatra, S., Bhanja, S., Das, D. and Barik, B. 2010 Formulation and in vitro characterization of xanthan gumbased sustained release matrix tablets of isosorbide-5mononitrate. Iran J. Pharm. Res. 9, 13-19.

8. Chaibva, F., Khamanga, S. and Roderick, B. 2010. Swelling, erosion and release characteristics of sulbutamol sulfate from hydroxy propyl methyl cellulose-based matrix tablets. Drug development and Industrial Pharmacy. 36, 1497-1510.

9. Matsuo, M., Nakamura, C., Arimori, K. and Nakano, M. 1995. Evaluation of hydroxyethylcellulose as a hydrophilic swellable material for delayed-release tablets. Chem. Pharm. Bull. 43, 311-314.

10. Halsas, M., Ervasti, P., Veski, P., Jürjenson, H. and Marvola, M. 1998. Biopharmaceutical evaluation of time-controlled press-coated tablets containing polymers to adjust drug release. Eur. J. Drug Metabol. Pharmacokin. 23, 190-195.
11. Gonzalez- Rodrigueg, M.L., Fernandez-Hervas, C.I. and Rabasco, A.M. 1997. Design and evaluation of new central core matrix tablet. Int. Pharma. 146, 175-180.

12. Maheshwari, R.K., Rathore, A., Agrawal, A. and Gupta, M.A. 2011. New spectrophotometric estimation of indomethacin capsules with niacinamide as hydrotropic solubilizing agents. Pharm. Methods 2, 184-188.

13. Higuchi, T. 1963. Mechanism of sustained-action medication. Theoretical analysis of rate of release of solid drugs dispersed in solid matrices. J. Pharm. Sci. 52, 11451149 .

14. Rajesh, K.S., Venkataraju, M.P. and Gowda, D.V. 2009. Effect of hydrophilic natural gums in formulation of oral-controlled release matrix tablets of propranolol hydrochloride. Pak. J. Pharm. Sci. 22, 211-219.

15. Baumgartner, S., Pavil, M. and Kristl, J. 2008. Effect of calcium ions on the gelling and drug release characteristics of xanthan matrix tablets. Eur. J. Pharm. Biopharm. 69, 698707.

16. Lin, S.Y., Li, M.J. and Lin, K.H. 2004. Hydrophilic excipients modulate the time lag of time-controlled disintegrating presscoated tablets. AAPS Pharm. Sci. Tech. 5, 54.

17. Lee, B.J., Ryu, S.G. and Cui, J.H. 1999. Controlled release of dual drug-loaded hydroxypropyl methyl cellulose matrix tablet using drug-containing polymeric coatings. Int. J. Pharm. 188, 71-80

18. Sirkiä, T., Niemi, A., Marvola, M., Lindqvist, T. and Happonen, I. 1994. Effect of potassium carbonate and viscosity grade of hydroxypropyl methyl cellulose on bioavailability of furosemide from press coated prolongedrelease tablets. S.T.P. Pharma. Sci. 4, 257-263.

19. Patadia, R., Vora, C., Mittal, K. and Mashru, R. 2015. Investigating effects of hydroxypropyl methyl cellulose (HPMC) molecular weight grades on lag time of press-coated ethylcellulose tablets. Pharm. Drug Dev. Technol. 1, 1-9. 